\title{
DesCENTRALIZACIÓN Y REACTIVACIÓN DE LA ECONOMÍA NACIONAL
}

\author{
Leoncio Javier Melgarejo \\ Docente - Facultad de Ciencias Contables
}

\begin{abstract}
Resumen
Con las experiencias de países hoy considerados grandes potencias, en los que el eje del despegue del desarrollo de su economía nacional han sido las micro y pequeñas empresas; generadoras del $98 \%$ del empleo y autoempleo de la Población Económicamente Activa;.así como el desarrollo socioeconómico integral del Perú está donde termina los confines de la absorbente y sin futuro de Lima, Capital de la República y demás ciudades concentradas desordenada y tugurizadamente; se viene implementando tanto directivas como ciertos programas que incentivan la creación, promoción, formalización, financiamiento, acceso a la información, mercados y servicios tecnológicos de las micro y pequeñas empresas denominadas como MYPES.
\end{abstract}

Así como se implementaron ciertos incentivos tributarios, al darse el D. L. 705, como el Registro Único, Régimen Simplificado y el Régimen Especial, también se han implementado ciertos programas con la vigente Ley de la Formalización y Promoción de las MYPES; entre ellos tenemos: PRODAME, BONOMYPES, CODEMYPES, etc, los mismos que han sido ponderados con la nueva Ley de Gobiernos Locales, ampliando sus alcances, atribuciones y participaciones de las municipalidades en la Promoción y Formalización de estos entes económicos, aunque aún existen motivos que mantienen a las PYMES en tanta informalidad y las concentra en los centros urbanos.

Palabras clave: Micro y pequeñas empresas, regionalización, entes financieros, capacidad productiva.

\section{INTRODUCCIÓN}

La Regionalización del país va más allá de lo proyectado. Esto, a iniciativa de los mismos gobiernos regionales, busca nuevas integraciones en grandes bloques regionales, paralograr mejor el desarrollo de los pueblos siempre olvidados por los poderes del Estado Centralista actual; dependiendo también estas proyecciones de la benevolencia del Poder Ejecutivo para llevara cabo el referéndum programado para el presente año para decidir históricamente sus destinos propios.
LOS EFECTOS NEGATIVOS DE LA RECESIÓN AFECTAN MÁS A LA ECONOMÍA URBANA

Los estragos del fenómeno económico que atraviesa la sociedad peruana por la recesión de la Producción Nacional tienen mayor incidencia en la población marginal de las orbes que han crecido desmesurada y desordenadamente.

Las poblaciones obreras o proles, ante la paralización de los entes manufactureros 
donde antes se ocupaban, se encuentran en situaciones inhumanas, convirtiéndose en "lacras sociales", seres improductivos y precarios. No obstante, la mayoría de ellas invaden calles, plazas, parques, etc., tratando de expender algunos productos, generalmente de consumo inmediato.

En tanto la Clase Media o la Pequeña Burguesía, confor mada por técnicos y profesionales, que trabajaban en las estructuras burocratizadas de las empresas del Estado, hoy privatizadas, y otros que exceden de las colapsadas instituciones públicas, al igual que los excedentes o cesados de las empresas privadas paralizadas siguen el mismo destino de los proles, que en la actualidad ya ni siquiera son taxistas sino mototaxistas, en el afán de salir de su desesperada situación labriega.

\section{CONSORCIOS DE LAS MIMYPES CENTRALIZADAS SON PALIA- TIVOS MOMENTÁNEOS}

La aparición de los conglomeradosentes productivos o el fenómeno de los llamados "provinciales industriales", que se encuentran ubicados en la Capital, como es el caso del Complejo de Gamarra, el conglomerado de metalmecánica de la "Parada", las manufactureras de mobiliarios de Villa Salvador, los de metal mecánica, electrónica o electrodomésticos de las Malvinas en la Av. Argentina, el conglomerado frutiagrícola, ode productos procedentes del contrabando puneño, etc.; así como de las demás ciudades concentradas, como son los fabricantes de calzado de la Esperanza - Porvenir de Trujillo, la Asociación de los Productores Agroindustriales dela Región Incaen Cusco, la industrialización artesanal de Huaraz,
Cajamarca, Puno, Huancayo, Ucayali, etc. tienen que proyectarse en la integral descentralización productiva a largo plazo.

\section{MYPES FINANCIERAS TAMBIÉN SE PROYECTANA DESCENTRALIZARSE}

Por otra parte, cuantificar a los entes financieros que funcionan informalmente es difícil, ya que estos no se registran en ninguna parte del fisco nacional ni local; pero existen grandes movimientos financieros en las esferas descentralizadas del país que cotidianamente financian a nuevos negociantes que aparecen en los diferentes rubros de la vida económica regional y local con proyección nacional e internacional.

Mediante el siguiente cuadro de informe estadístico podemos analizar la ubicación centralista de establecimientos por la naturaleza del giro de los negocios.

De las cuales, las cinco primeras actividades conforman el $43 \%$ de los establecimientos constituyen actividades de naturaleza de consumo y solo el $10 \%$ representa a las actividades manufactureras. El sector textil-confecciones es una de las actividades manufactureras más dinámicas, representa el $8 \%$ de las exportaciones y el $30 \%$ de las exportaciones tradicionales; su contribución al Producto Bruto Nacional manufacturero se ubica alrededor del $12 \%$ al $15 \%$ en los últimos años con un crecimiento sostenido. En tanto, las divisas originadas por el valor agregado que arroja en las exportaciones creció desde 1990 en un promedio de 218 millones de dólares anuales en la última década; haciendo que las exportaciones peruanas en textilería y confecciones represente el $0,1 \%$ del 


\begin{tabular}{|c|c|c|c|c|c|c|}
\hline & 2002 & $\%$ & 2003 & $\%$ & 2004 & $\%$ \\
\hline Bodegas & 19319 & 26 & 44299 & 25,6 & 48425 & 24 \\
\hline Restaurantes & 5203 & 7,2 & 14286 & 8,9 & 17925 & 9,5 \\
\hline Vulcanizadoras- planchados & 1950 & 2,7 & 5077 & 3,6 & 6950 & 3,5 \\
\hline Peluquerías - salón de belleza & 1691 & 2,3 & 5209 & 3,8 & 6950 & 3,4 \\
\hline Farmacias & 1577 & 2,2 & 3938 & 2,5 & 4575 & 2,4 \\
\hline Confecciones & 2014 & 2,8 & 3779 & 2,4 & 5345 & 3,2 \\
\hline Ferreterias & 1786 & 2,5 & 3381 & 2,1 & 4628 & 2,5 \\
\hline Librerías & 1817 & 2,2 & 3213 & 2,0 & 3800 & 2,8 \\
\hline Metalmecánica & 1168 & 1,6 & 2703 & 1,9 & 2950 & 2,1 \\
\hline Productos de madera & 868 & 1,2 & 1577 & 1,5 & 2200 & 2,0 \\
\hline Panaderias & 1216 & 1,7 & 2345 & 1,8 & 2560 & 2,3 \\
\hline Calzados & 865 & 1,3 & 2045 & 1,7 & 2550 & 2,2 \\
\hline Hostales & 805 & 1,1 & 1400 & 1,4 & 2025 & 18 \\
\hline Otras actividades & 14479 & 26,8 & 64486 & 40,8 & 70643 & 39 \\
\hline
\end{tabular}

comercio mundial y así ingrese a la competencia potencial y ponderada a la producción textilera mexicana, ubicada entre los primeros puestos del mundo. Con respecto a la generación de puestos de trabajo, el sector textil por cada millón de dólares invertidos genera 120 puestos de trabajo en más de 120000 empresas dedicadas a la textilería y confección ubicados en los grandes centros productores -comerciales, principalmente en la ciudad deLima, por ejemplo: el Complejo Gamarra, los Centros Feriales de Av. Grau, Mercado
Central, Polvos Azules, Polvos Rosados, etc., tanto del mercado formal e informal.

El mercado informal es bastante superior a la dimensión de la producción formal porque utiliza mano de obra barata, no paga tributos e inclusive piratea marcas. La composición porcentual del sector textilconfecciones, tomando en cuenta el tamaño de empresas en relación a la generación de empleos y al valor de exportaciones registradas al 31 de diciembre de 2001 y es la siguiente:

\begin{tabular}{|l|c|c|c|}
\hline \multicolumn{1}{|c|}{ Tamaño de empresas } & N. ${ }^{\circ}$ de empresas & Valor de exportación & Empleos \\
\hline MIPYMES & 99,90 & 18 & 92,40 \\
\hline GRANDES & 0,10 & 82 & 7,20 \\
\hline Total & $\mathbf{1 0 0 , 0 0}$ & $\mathbf{1 0 0}$ & $\mathbf{1 0 0 , 0 0}$ \\
\hline
\end{tabular}

Fuente: DRITINCI. 
En la actualidad las micro, pequeñas y medianas empresas del sector textil confección representan el $99,90 \%$ del número de empresas descentralizadas $\mathrm{y}$ exportan de su producción en un $18 \%$, creando puestos de trabajo un promedio de $92,40 \%$ de la ocupación nacional.

\section{MIPYMES DESCENTRALIZADOS EN RELACIÓN A LA CONCEN- TRACIÓN CAPITALINA}

Según las actividades económicas que realizan las diversas micro, pequeñas y medianas empresas, estas están concentradas en la Capital de la República. A continuación se expone en el siguiente cuadro comparativo:

\section{CONCLUSIONES}

Las MIPYMES representan el $98 \%$ de los entes económicos que generan nuestra Producción Nacional, en Lima se ubica el $90 \%$, para que verdaderamente encausen la reactivación de la Economía Nacional estas requieren mayores normas o directivas vía los gobiernos regionales y locales para la urgente descentralización económica y social del país.

Es necesario que el Gobierno Central cumpla un papel de promotor con participación directa, dictando normas que incentiven tributariay administrativamente.

Es impostergable la participación competente de los profesionales, principalmente del campo empresarial y

\begin{tabular}{|c|c|c|c|c|c|}
\hline \multirow{2}{*}{ Subsector } & \multirow{2}{*}{ Departamentos } & \multicolumn{2}{|c|}{ Establecimientos } & \multicolumn{2}{|c|}{ Ventas } \\
\hline & & N. ${ }^{\circ}$ & $\%$ & Montos & $\%$ \\
\hline \multirow{7}{*}{ 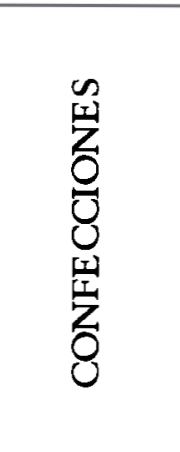 } & Lima & 18093 & 74,99 & 700691.00 & 92,59 \\
\hline & Arequipa & 1035 & 4,29 & 5801.00 & 0,77 \\
\hline & La Libertad & 963 & 3,95 & 1975.00 & 0,26 \\
\hline & Junín & 913 & 3,78 & 546.00 & 0,07 \\
\hline & Lambayeque & 863 & 3,58 & 2342.00 & 0,31 \\
\hline & Callao & 738 & 3,06 & 43905.00 & 5,80 \\
\hline & Los demás & 1531 & 6,35 & 1491.00 & 0,20 \\
\hline & Total & 24126 & 100,00 & 756750.00 & 100,00 \\
\hline
\end{tabular}

En Lima, ciudad que no tiene mayor proyección de desarrollo social ni económico, se ubica el $92 \%$ de las micro, pequeñas y medianas empresas. Otras ciudades que albergan un gran número de grandes empresas son Arequipa, Trujillo, etc. social de concepción regionalista. Así como también la for mación deincidencia gerencial de otras profesiones. 


\section{RECOMENDACIONES}

- El Poder Legislativo debe modificar e implementar normas o directivas que encausen integralmente a la descentralización de las PYMES.

- Los gobiernos regionales y locales deben otorgarincentivosy facilidades de trámites administrativos sustanciales e integrales para la constitución, captación y formalización de las PYMES en cada una de sus jurisdicciones descentralizadas.

- Desde la eliminación del RUC para las personas naturales, sustituyéndolo también para la identificación tributaria, así como para las personas jurídicas, la implementación del Registro Jurídico a cambio del RUC, se requieren mayores y sustanciales normas tributarias hasta consolidar los entes económicos descentralizados para que luego el Estado pueda gravar mejor.

\section{REFERENCIAS}

1. DRITINCI. Fuentes Estadísticas.

2. INEI. Fuentes Estadísticas.

3. Proyecto "Incentivos Tributarios a los MYPES Descentralizados”.

4. Villarán, Fernando. Pasión y gloria de las Pequeñas Empresas, 1998. 